\title{
Influence of Psychological Distress in Patients with Hypoallergenic Total Knee Arthroplasty. Treatment Algorithm for Patients with Metal Allergy and Knee Osteoarthritis
}

\author{
Pilar Peña ${ }^{1}$, Miguel A. Ortega ${ }^{2,3, * \oplus \text {, Julia Buján }}{ }^{2,3}$ and Basilio De la Torre ${ }^{3,4,5}$ \\ 1 Orthopedic Surgery and Traumatology Service, Virgen de la Luz Hospital, 16002 Cuenca, Spain; \\ pilarpf1204@yahoo.es \\ 2 Departments of Medicine and Medical Specialities, Faculty of Medicine and Health Sciences, \\ University of Alcalá, Alcalá de Henares, 28801 Madrid, Spain; mjulia.bujan@uah.es \\ 3 Ramón y Cajal Institute of Sanitary Research (IRYCIS), 28034 Madrid, Spain; bjtorre@gmail.com \\ 4 Department of Surgery, Medical and Social Sciences, Faculty of Medicine and Health Sciences, \\ University of Alcalá, Alcalá de Henares, 28801 Madrid, Spain \\ 5 Service of Traumatology, University Hospital Ramón y Cajal, 28034 Madrid, Spain \\ * Correspondence: miguel.angel.ortega92@gmail.com; Tel.: +34-65-855-50-21; Fax: +34-91-885-48-85
}

Citation: Peña, P.; Ortega, M.A.; Buján, J.; De la Torre, B. Influence of Psychological Distress in Patients with Hypoallergenic Total Knee Arthroplasty. Treatment Algorithm for Patients with Metal Allergy and Knee Osteoarthritis. Int. J. Environ. Res. Public Health 2021, 18, 5997. https://doi.org/10.3390/ ijerph18115997

Academic Editors: Umile Giuseppe Longo and Vicenzo Denaro

Received: 20 April 2021

Accepted: 29 May 2021

Published: 3 June 2021

Publisher's Note: MDPI stays neutral with regard to jurisdictional claims in published maps and institutional affiliations.

Copyright: (c) 2021 by the authors. Licensee MDPI, Basel, Switzerland. This article is an open access article distributed under the terms and conditions of the Creative Commons Attribution (CC BY) license (https:// creativecommons.org/licenses/by/ $4.0 /)$.
Abstract: The outcome in total knee arthroplasty (TKA) depends on multiples factors, among them is the psychological condition. In addition, up 15 to $30 \%$ of the patients that undergo TKA show little or no improvement after surgery, which implies the diagnosis of a painful TKA is a challenge for the orthopedic surgeon, who must rule out a possible metal allergy (MA). It is considered an exclusion diagnosis. Due to the complex relationship between psychological condition and MA, and according to the worse results in patients treated with a hypoallergenic TKA, we asked: (1). What degree of psychological distress (PD) is present in patients who have a hypoallergenic TKA, and how does it influence the results of quality of life (QoL) and functional capacity. (2). Can we develop a new algorithm for patients with a possible MA that improves the outcomes? A pragmatic clinical study was carried out that included patients who underwent hypoallergenic TKA during three consecutive years. Quality of life and functional capacity were measured with (Western Ontario McMaster Universities Osteoarthritis Index) WOMAC index, the Short Form 12 questionnaire (SF-12) questionnaire, and the The EQ-5D-5L questionnaire essentially consists of two pages: the EQ-5D descriptive system and the EQ visual analogue scale (EQ VAS) (Euro-QoL-5D L-VAS (EQ5D)), in all patients. To assess PD, a Psychological Distress Score was developed. SPSS software was performed to statistical analysis, and Student's test for independent variables with a $p<0.005$ as statistically significant. A total of 72 anallergic TKAs in 64 patients were treated during this period; $31.3 \%$ of these patients showed features of PD before the surgery. According with the severity of the PD, $60 \%$ were classified as severe, $10 \%$ as moderate and $30 \%$ as mild. Patients with PD had statistically significant worse results on the final WOMAC, SF-12, and EQ5D questionnaires. The final scores of the physical subscale of the SF-12 and EQ5D showed better results in patients diagnosed by psychiatrist. Up to one third of the patients with hypoallergenic TKAs have PD, and their results are clearly inferior to those patients with MA without PD. When PD was diagnosed according with Psychological Distress Score, patients should be carefully assessed in order to determine if a specialist referral is recommended. According with our results, PD should be assessed either by the PCP or by us. If the $\mathrm{PD}$ is confirmed, a psychiatry referral is then requested for better preoperative management and treatment. We believe that this approach would lead to better TKA outcomes.

Keywords: psychological distress; quality of life; total knee arthroplasty

\section{Introduction}

Total knee arthroplasty (TKA) is the definitive treatment for knee osteoarthritis (OA), reducing pain and providing a better quality of life [1-7]. However, 15 to $30 \%$ of the patients 
that undergo TKA, show little or no improvement after surgery [6-8]. Among other factors, this high percentage is related to the surgical technique and implant selection $[1,2,9,10]$. Consequently, local and systemic adverse effects related to the implant must be considered. In this aspect, metal allergy (MA), specifically to nickel (N) and chrome-cobalt (Cr-Co) stands out [10]. Metal skin hypersensitivity (MSH) is currently quite controversial in the setting of TKA. MSH is present in $25 \%$ of the painless TKAs and in up to $60 \%$ of the painful TKAs [11,12]; not being clear if detected preoperatively predisposes the patient to implant-related problems. However, despite the high incidence of $\mathrm{MSH}, 20-30 \%$ of the general population, few cases have been reported with a true hypersensitivity in the periprosthetic tissue $[10,13]$. On the other hand, many authors recommend implanting hypoallergenic prosthesis to avoid potential problems. Nevertheless, the diagnosis of painful TKA secondary to MA is still considered an exclusion diagnosis [14,15]. Another factor that is related to the outcomes in TKA is the psychological status of the patient. Up to one third of the patients that undergo TKA may have psychological distress (PD) [16,17], a term that encompasses a group of psychological symptoms, including anxiety, depression, and somatization, which affect the outcome of the surgery $[18,19]$. Due to the complex relationship of both MA and PD and according to the worse outcomes of hypoallergenic implants [17] previously published by our group, we decided to study what grade of PD is present in the patients that undergo TKA. Our primary objective was to analyse the influence that PD has on the outcomes from the hypoallergenic TKAs, and to try to develop, according to the study results, new algorithms that guide preoperative decision making and, consequently, optimize surgical results.

\section{Patients and Methods}

\subsection{Study Design}

A retrospective pragmatic clinical study was conducted to make decision in the clinic and measure the effectiveness of interventions as they are routinely used. The study was approved by the Ethical Committee and Institutional Review Board. All patients were informed on the study purposes and consent forms were obtained from the participants.

\subsection{Patients}

Inclusion criteria included patients who underwent TKA for primary knee OA between January 2013 and December 2015 at our institution. A total of 228 patients with 245 TKA were identified, being 76 of those hypoallergenic TKA (Oxinium ${ }^{\circledR}$ from Smith \& Nephew, Memphis, TN, USA).

The exclusion criteria included, apart from the patients not allergic to metals with $\mathrm{Cr}$ Co TKA (162 TKA in 153 patients), they were the following: patients who underwent TKA for post-traumatic OA and those with previous osteotomies around the knee [6], deceased patients [1], those who are not willing to answer the questionnaires [3] and a patient with two different implants in both knees (Cr-Co and hypoallergenic). 72 hypoallergenic RTAs in 64 patients formed the final sample of the study (Figure 1).

Preoperatively, patients were interrogated on the possibility of MSH. Those who claimed to have it, had a skin patch test (SPT) performed. If the result of the SPT was positive, an Oxinium ${ }^{\circledR}$ hypoallergenic TKA was implanted at the time of surgery.

Patients were operated on by the same surgical team and with a standardized surgical technique: epidural anesthesia, prophylactic antibiotics (cefazolin $2 \mathrm{~g}$ IV or vancomycin $1 \mathrm{~g} 30$ or $60 \mathrm{~min}$ before skin incision), tourniquet and medial parapatellar approach. The implant used in every case was the Genesis II (Smith \& Nephew, Memphis, TN, USA), composed by a cemented Oxinium ${ }^{\circledR}$ femoral component, cemented titanium tibial tray (Ti6Al4V), and a posterior-stabilized (PS) polyethylene (UHWMPE). Patellar replacement was performed in patients with Outerbridge grade IV patellar OA determined at the time of the surgery. Skin closure was performed with monofilament suture (Prolene 3/0). A drain was left in place and removed $24 \mathrm{~h}$ after the surgery. All patients initiated early weight- 
bearing $24 \mathrm{~h}$ after the surgery and rehabilitation was maintained for 6 weeks after hospital discharge. Patients were followed up in clinics at 4 weeks, 3, 6, 12, and 24 months.

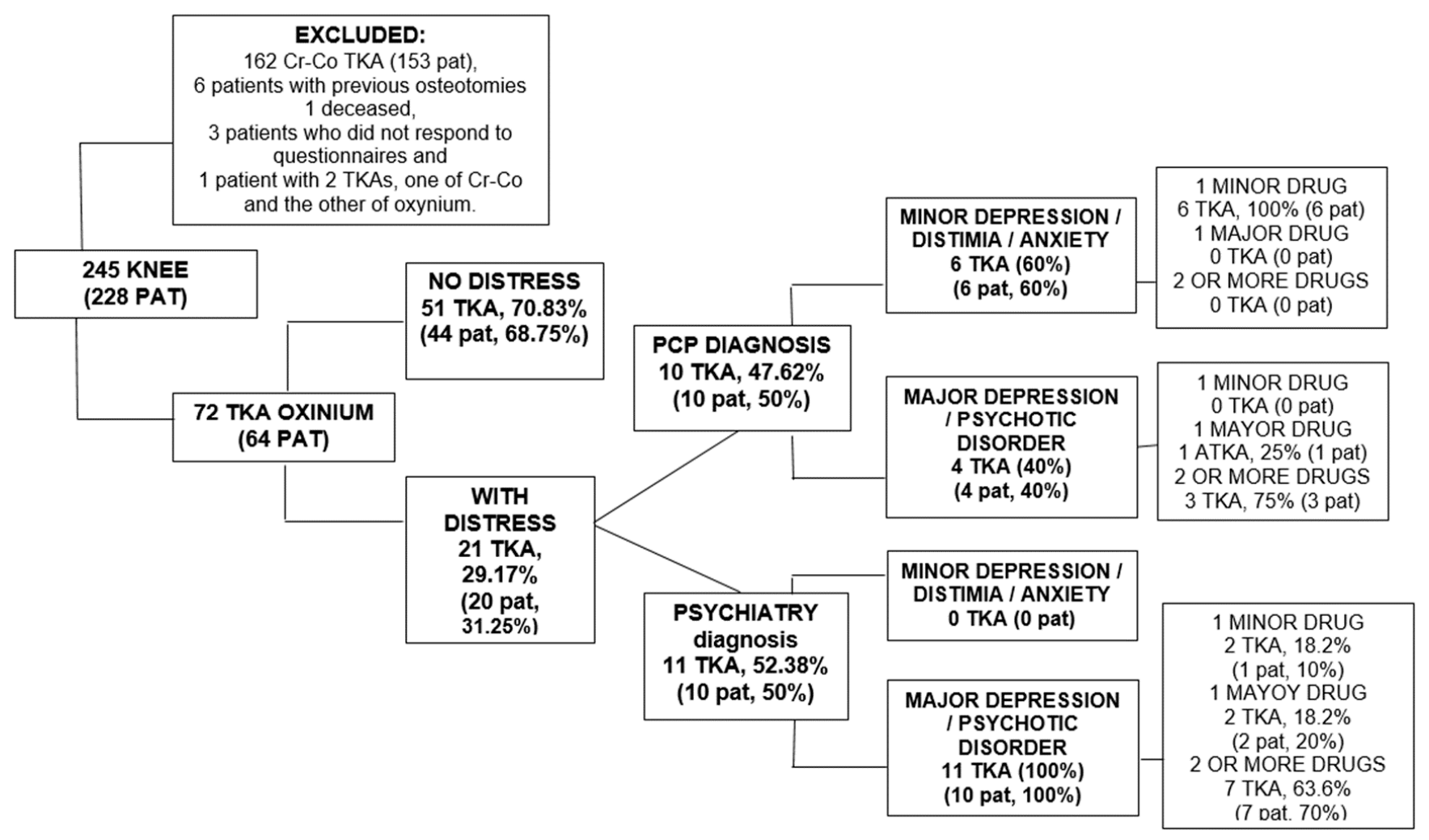

Figure 1. Patients flow chart with hypoallergenic TKA.

\subsection{Covers Variables and Data Collection}

Data was collected from the medical files and included age, gender, body mass index (BMI), laterality (right/ left/ both), mental health conditions at the time of surgery, patellar prosthesis (yes/no), time from the surgery, and complications.

Time after intervention (months) is the mean time from when a patient was intervened until the telephone calls for the study were made.

Mental health conditions at the time of surgery were collected after data collection from the digital medical record (preoperative anesthesia form, form from your primary care physician (PCP) and psychiatry/psychology form, if any). Initially, those patients with PD (yes, $n=21$ patients) or without PD (no, $n=51$ patients) were determined. Subsequently, we made an assessment of the type of PD they suffered through the questionnaire carried out together with the Psychiatry Service.

\subsection{Questionnaires}

Quality of life and function were evaluated by three questionnaires: Western Ontario and MacMaster (WOMAC) OA Index [2,9,16,19-21], health questionnaire Short-Form-12 (SF-12) [19,22-26], and Euro-QoL-5D L-VAS (EQ5D) [27-29].

To assess preoperative PD, a Psychological Distress Score was developed along with the Psychiatry Department. This is a tool created ad hoc for this study. Three parameters were considered for its elaboration: past psychiatric history, type of condition, and number of medications taken (Table 1). Past psychiatric history was based on previous records of psychological/psychiatric diagnoses by their primary care physician (PCP) or psychiatrist. The type of condition was subdivided in two groups. First group included patients with diagnosis of minor depression, dysthymia, or anxiety. Second group incorporated those with diagnosis of major depression or psychotic disorder. The number of medications taken was subclassified in three categories: anxiolytic or minor antidepressant, major 
antidepressant, and two or more medications. The final sum of each of the three items gives a final score for mild ( 3 points), moderate ( $4-5$ points), and severe (6-7 points) preoperative $\mathrm{PD}$. The final PD, therefore, refers to the final result of the ad hoc questionnaire that each patient presents before being operated on for knee OA. Patients with no distress were assigned a 0 score, while a final score of 1-2 was impossible to obtain because those patients without mental health conditions had no diagnoses nor take medications. As those data were collected retrospectively, we decided to develop this score to avoid time-related biases that may had happened with the use of standardized prospective scales such as Hamilton, Goldberg, or PHQ-15 questionnaires. Data was retrieved from the medical files by one of the authors and by a nurse who phone called the patients. Demographic data and psychological distress were collected retrospectively while the questionnaires were completed after the study began. The postoperative PD assessment is included in the mental SF-12 and EQ-5D index questionnaires since they are questionnaires that we carry out once the patients have already been operated on.

Table 1. Psychological distress score.

\begin{tabular}{c}
\hline Psychological Distress Psychiatric History \\
0: no diagnosis of psychiatric pathology \\
1: diagnosis by family doctor \\
2: diagnosis by the Psychiatry Service \\
Type Psychiatric Pathology \\
0: no pathology \\
\hline 1: minor depression or dysthymia or anxiety \\
2: major depression or psychotic disorder \\
\hline No. and type of drugs administered to the patient \\
0: no medication \\
1: take a minor drug \\
2: take a major drug \\
3: take two or more drugs \\
Final score \\
\hline 1: 3 points, mild psychiatric pathology \\
2: 4-5 points, moderate psychiatric pathology \\
3: 6-7 points, severe psychiatric pathology
\end{tabular}

\subsection{Statistical Analysis}

Statistical analysis was performed with the SPSS software (version 24, SPSS Inc., IBM, Armonk, NY, USA). The results are presented as mean \pm standard deviation (SD) or absolute value and percentage. Student's $\mathrm{T}$ test for independent variables was used to analyze if the PD had an influence in the outcomes from the questionnaires in the hypoallergenic TKAs. A $p$ value of $<0.05$ was considered as statistically significant.

\section{Results}

\subsection{Cohort}

Table 2 summarizes the cohort characteristics of the 72 hypoallergenic TKA in 64 patients. 
Table 2. Descriptive characteristics of the study sample. The results are presented as the mean \pm standard deviation (SD) or total value and percentage. Body Mass Index (BMI), Western Ontario McMaster Universities Osteoarthritis Index (WOMAC), Short Form 12 questionnaire (SF-12 questionnaire), The EQ-5D-5L questionnaire essentially consists of 2 pages: the EQ-5D descriptive system (Euro-Qol-5D) and Visual Analog Scale (VAS).

\begin{tabular}{|c|c|}
\hline & TKA Hypoallergenic $n=72$ \\
\hline Average age (years) & $72.30 \pm 6.03$ \\
\hline Women, $n(\%)$ & $70(92.1)$ \\
\hline BMI $\left(\mathrm{kg} / \mathrm{m}^{2}\right)$ & $32.12 \pm 5.08$ \\
\hline \multicolumn{2}{|c|}{ Weight, $n(\%)$} \\
\hline Normo-weight & $3(3.9)$ \\
\hline Overweight & $24(31.6)$ \\
\hline Obesity & $49(64.5)$ \\
\hline Time after intervention (months) & $27.49 \pm 8.666$ \\
\hline Patellar component, $n(\%)$ & $11(18)$ \\
\hline \multicolumn{2}{|c|}{ Laterality } \\
\hline Right & $36(50)$ \\
\hline Left & $23(38.9)$ \\
\hline Both & $8(11.1)$ \\
\hline Psychiatric history, $n(\%)$ & $21(29.17)$ \\
\hline Associated complications, $n(\%)$ & $12(15.8)$ \\
\hline \multicolumn{2}{|c|}{ WOMAC } \\
\hline Total & $28.37 \pm 20.66$ \\
\hline Pain & $5.27 \pm 5.29$ \\
\hline Rigidity & $1.41 \pm 2.10$ \\
\hline Difficulty & $22.34 \pm 14.62$ \\
\hline \multicolumn{2}{|c|}{ SF-12 } \\
\hline Physical & $27.28 \pm 10.58$ \\
\hline Mental & $44.86 \pm 11.37$ \\
\hline \multicolumn{2}{|c|}{ EuroQoL-5D } \\
\hline Index & $0.65 \pm 0.32$ \\
\hline VAS & $53.86 \pm 34.94$ \\
\hline
\end{tabular}

\subsection{Psychological Distress in Patients with Hypoallergenic TKA}

A total of $31.3 \%$ of the patients $(29.17 \%$ of the TKAs) showed features of preoperative PD (Figure 1). Half of those patients were diagnosed by their PCP and half by their psychiatrist. Of the patients diagnosed by the PCP, 60\% had minor depression, dysthymia, or anxiety and all had either a minor antidepressant or an anxiolytic medication. Of the $40 \%$ that had major depression or psychotic disorder, 75\% were taking two or more medications and one patient had a major antidepressant. All patients that were diagnosed by Psychiatry of major depression or psychotic disorder were prescribed two or more medications in $70 \%$ of the cases.

Concerning the severity of the preoperative PD, $60 \%$ were classified as severe, $10 \%$ as moderate, and $30 \%$ as mild (Table 3 ). 
Table 3. Descriptive characteristics of the final preoperative Psychological Distress Score of hypoallergenic Oxinium TKA.

\begin{tabular}{ccccc}
\hline \multicolumn{5}{c}{ Psychological Distress Score } \\
\hline Psychological Distress & $\begin{array}{c}\text { 3 Points, } \\
\text { Mild }\end{array}$ & $\begin{array}{c}\text { 4-5 Points, } \\
\text { Moderate }\end{array}$ & $\begin{array}{c}\text { 6-7 Points, } \\
\text { Severe }\end{array}$ & Total \\
\hline$N$ patients (knee) (\% pat) & $6(6)[30]$ & 2(3) [10] & 12(12) [60] & 20 (21) [100] \\
\hline
\end{tabular}

\subsection{Results of the Questionnaires}

All comparisons are made with respect to pre-PD. We assess how the diagnosis of having or not having PD affects the results of the questionnaires (WOMAC, SF-12, and EQ-5D), the influence of PD diagnosed by the PCP or Psychiatry on the results of those questionnaires and, finally, how having minor or major depression contributes to the results of the pre-PD questionnaires.

The final WOMAC Total scores and the EQ5D index showed better results in patients without pre-PD (lower values). Furthermore, the physical and mental subscales of SF-12 and EQ5D VAS also showed better results in patients without PD (higher values in the questionnaires). All the results were statistically significant in comparison with the patients with hypoallergenic RTA and without previous PE versus the patients with PE (Table 4).

Table 4. Student's $t$ results for independent samples of preoperative psychological distress in patients treated with hypoallergenic implants with respect to the results of the questionnaires (WOMAC, SF-12 and Euro-Qol-5D). PD (psychological distress: YES n = 51 TKA, 44 patients; NO n = 21 TKA, 20 patients). The results are presented as the mean \pm standard deviation (SD).

\begin{tabular}{|c|c|c|c|c|}
\hline & \multirow{2}{*}{ PD } & \multicolumn{3}{|c|}{ TKA Hypoallergenic } \\
\hline & & Mean & SD & $p$ \\
\hline \multirow{2}{*}{ WOMAC Total } & Yes & 41.76 & 23.212 & \multirow{2}{*}{0.000} \\
\hline & No & 23.25 & 17.229 & \\
\hline \multirow{2}{*}{ SF Physical } & Yes & 25.269 & 10.048 & \multirow{2}{*}{0.015} \\
\hline & No & 32.804 & 10.058 & \\
\hline \multirow{2}{*}{ SF Mental } & Yes & 37.568 & 12.665 & \multirow{2}{*}{0.017} \\
\hline & No & 42.527 & 9.819 & \\
\hline \multirow{2}{*}{ EQ Index } & Yes & 0.84 & 0.25 & \multirow{2}{*}{0.019} \\
\hline & No & 0.71 & 0.28 & \\
\hline \multirow{2}{*}{ EQ VAS } & Yes & 35.14 & 33.600 & \multirow{2}{*}{0.013} \\
\hline & No & 61.00 & 33.004 & \\
\hline
\end{tabular}

When comparing the results of the questionnaires with those that diagnosed pre-PD, the final questionnaires of WOMAC Total and the EQ5D Index showed higher (worse) and lower (worse) results in Physical SF-12 and the EQ5D VAS in patients diagnosed by their PCP. Likewise, the final score of the SF-12 Mental physical subscale showed a higher (better) result in those diagnosed by their PCP. All these results, except the mental subscale of the SF-12, were statistically significant (Table 5). 
Table 5. Student's $t$ results for independent samples of preoperative hypoallergenic psychological distress and TKA and diagnosis of distress by PCP or psychiatry with respect to the results of the questionnaires (WOMAC, SF-12 and Euro-Qol-5D).

\begin{tabular}{|c|c|c|c|c|}
\hline & \multirow{2}{*}{ Diagnosis PD } & \multicolumn{3}{|c|}{ PD and TKA Hypoallergenic } \\
\hline & & Mean & SD & $p$ \\
\hline \multirow{2}{*}{ WOMAC Total } & PCP & 40.03 & 20.72 & \multirow{2}{*}{0.046} \\
\hline & Psychiatry & 30.24 & 15.275 & \\
\hline \multirow{2}{*}{ SF Physical } & PCP & 27.875 & 9.781 & \multirow{2}{*}{0.039} \\
\hline & Psychiatry & 32.432 & 10.984 & \\
\hline \multirow{2}{*}{ SF Mental } & PCP & 40.937 & 10.735 & \multirow{2}{*}{0.057} \\
\hline & Psychiatry & 38.652 & 9.54 & \\
\hline \multirow{2}{*}{ EQ Index } & РCP & 0.89 & 0.23 & \multirow{2}{*}{0.028} \\
\hline & Psychiatry & 0.81 & 0.25 & \\
\hline \multirow{2}{*}{ EQ VAS } & PCP & 36.04 & 30.93 & \multirow{2}{*}{0.05} \\
\hline & Psychiatry & 40.32 & 29.07 & \\
\hline
\end{tabular}

On the other hand, we confront the results of pre-PD both in patients with minor depression/dysthymia/anxiety and with major depression/psychotic disorder. WOMAC Total and EQ5D Index showed superior (worse) results in patients diagnosed with minor depression. The mental and physical subscales of the SF-12 and EQ5D VAS showed lower values (worse results) in those patients with minor depression. WOMAC Total, EQ5D Index, and EQ5D VAS were statistically significant compared to patients with hypoallergenic RTA, previous PD, and a diagnosis of minor depression (Table 6).

Table 6. Student $t$ results for independent samples of preoperative hypoallergenic psychological distress and TKA and diagnosis of minor depression/dysthymia/anxiety or major depression/psychotic disorder with respect to the results of the questionnaires (WOMAC, SF-12, and Euro- Qol-5D).

\begin{tabular}{|c|c|c|c|c|}
\hline & \multirow{2}{*}{ Type of DS Diagnosis } & \multicolumn{3}{|c|}{ PD and TKA Hypoallergenic } \\
\hline & & Mean & SD & $p$ \\
\hline \multirow{2}{*}{ WOMAC Total } & Minor depression & 41.32 & 19.793 & \multirow{2}{*}{0.039} \\
\hline & Major depression & 31.26 & 16.865 & \\
\hline \multirow{2}{*}{ SF Physical } & Minor depression & 26.114 & 9.546 & \multirow{2}{*}{0.056} \\
\hline & Major depression & 29.984 & 10.433 & \\
\hline \multirow{2}{*}{ SF Mental } & Minor depression & 36.67 & 9.98 & \multirow{2}{*}{0.057} \\
\hline & Major depression & 40.154 & 9.17 & \\
\hline \multirow{2}{*}{ EQ Index } & Minor depression & 0.88 & 0.26 & \multirow{2}{*}{0.04} \\
\hline & Major depression & 0.83 & 0.23 & \\
\hline \multirow{2}{*}{ EQ VAS } & Minor depression & 35.64 & 28.76 & \multirow{2}{*}{0.048} \\
\hline & Major depression & 41.23 & 28.47 & \\
\hline
\end{tabular}

\section{Discussion}

To our knowledge, this is the study with the largest sample analyzing patients with hypoallergenic TKAs and PD. The relatively large sample size is due to the number of patients that self-report having MA. As stated previously, there is controversy regarding MA and implant failure. Despite SPT having a strong correlation with MA, no causal relationship has been established between dermal reactions and implant failure [30,31]. Thus, is not surprising that only $31.25 \%$ of the patients show histological changes in the 
periprosthetic tissue. Bravo et al. [32] were the first to deny a causal relationship between MA and TKA failure, suggesting that preoperative skin tests may not be necessary. It is not clear if a positive SPT represents a real MA. In fact, despite being quite sensitive, false negatives are present in MA tests $[13,29,33]$. Therefore, either cutaneous MA has no correlation with deep MA, either a positive SPT is not an adequate test to determine a deep MA. If, as we support, both premises are correct, SPT would be an unnecessary test in the setting of TKA. This could mean that even in the presence of a positive SPT is not mandatory to implant and hypoallergenic TKA. Based on this, our practice has changed and now we only ask for a SPT in those patients who self-report two or more symptoms of MA dermatitis: redness, skin inflammation, thickened-scaled skin, erythema, or local pruritus. If they do not report these symptoms, we do not perform an SPD, because just a self-reported intolerance to imitation jewelry is not enough to diagnose skin MA [34]. In this study, all patients who underwent hypoallergenic TKA underwent patch testing and gave a positive result for allergy to metals despite the fact that there are controversies in the literature with whether to perform them or not.

As the relationship between MA and PD has been reported in the past, we studied how this psychological disorder affects TKA's outcomes [17]. Up to one third of the patients with hypoallergenic TKAs have pre-PD, and their results are clearly inferior to those patients with MA without pre-PD. This fact may be related to the association between stress and depressed immune response, both humoral and cellular, being possible that patients diagnosed with PD present a higher incidence of MA [35,36].

On the other hand, when pre-PD was diagnosed by the PCP, the WOMAC Total, SF-12 Physical, EQ5D Index, and VAS scores were significantly worse, while the SF-12 Mental was slightly better in patients previously diagnosed by their PCP, although not statistically significant between both groups. In addition, patients diagnosed with minor depression, dysthymia, or anxiety treated by their PCP had lower scores on all questionnaires than patients with major depression/psychotic disorder treated by a psychiatrist. These results may indicate that the PCP may incur underdiagnosis, misdiagnosis, or inappropriate treatment. Therefore, when a patient with MA is identified by TKA, pre-PD should be carefully evaluated to determine if referral to a specialist is recommended, since if the treatment is prescribed by a psychiatrist, better functional results could be expected (Figure 2).

The outcomes may be also influenced by the patella in those patients who had patellar resurfacing. Due to the small number of patients that had the patella prosthesis implanted $(18 \%)$, we do not believe that this may had influenced the results, which is also supported by previous studies [37,38].

The expected increase in the demand of TKA in the years to come require further research on its possible failure causes. The uncertainty that surrounds MSH and its potential effects on TKA outcomes require a thorough analysis. Based on the results of our study, we recommend considering certain recommendations [34] in the patients with self-reported MA. We propose that in the setting of confirmed signs of dermatitis (redness, skin inflammation, thickened-scaled skin, erythema, or local pruritus) a SPT is performed. If these symptoms are not present we do not indicate the SPT but instead we do assess $\mathrm{PD}$, due to their high association rate. In our opinion, PD should be assessed either by the $\mathrm{PCP}$ either by us. If the pre-PD is confirmed, a psychiatry referral is then requested for a better preoperative management and treatment. We believe that this approach would lead to better TKA outcomes. 


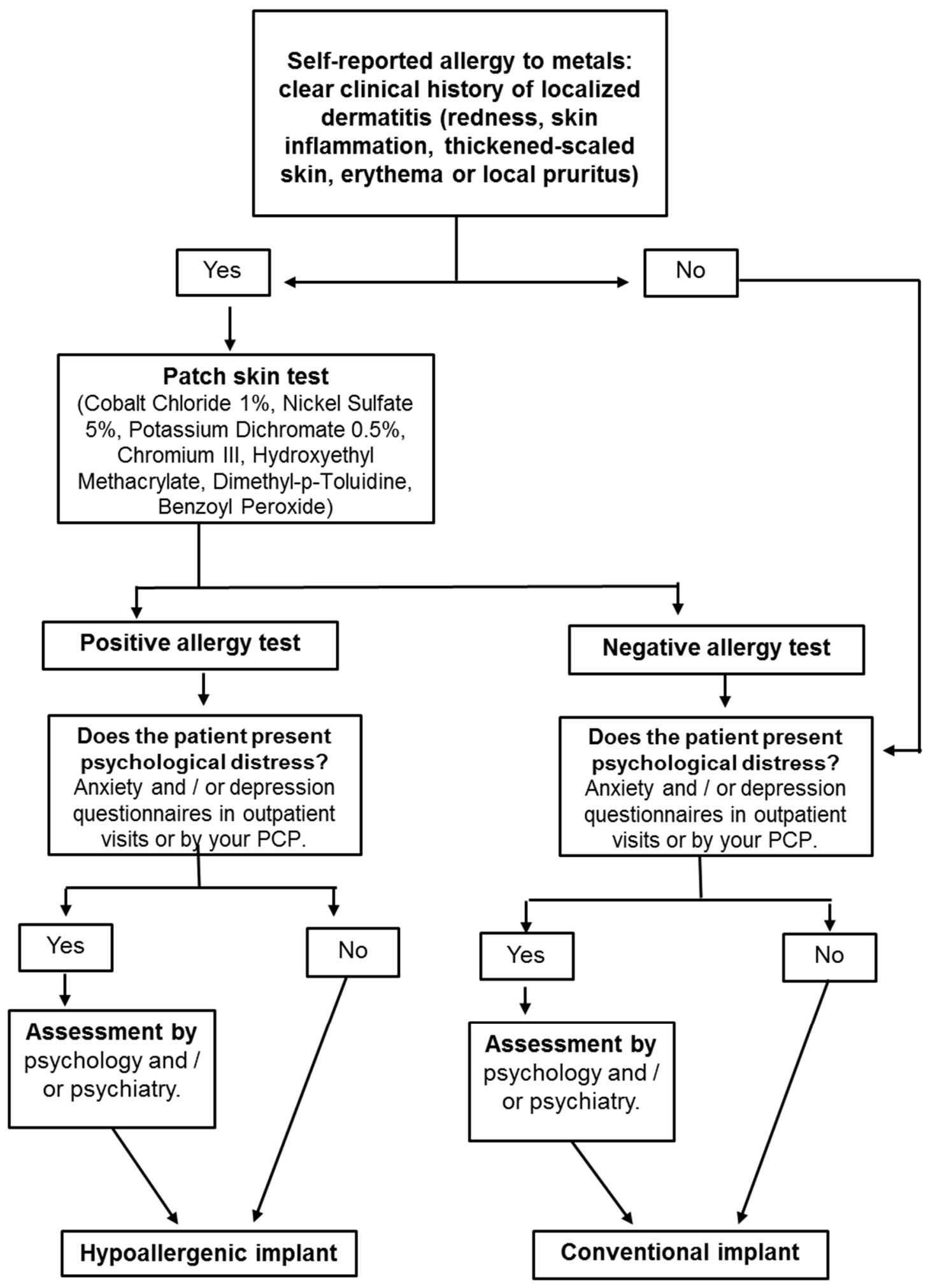

Figure 2. Algorithm for the diagnosis and treatment of metal allergy in a patient with knee osteoarthritis.

\section{Conclusions}

In conclusion, having pre-PD means less satisfaction with the final result of hypoallergic TKA surgery in patients with MA. We highlight the importance of adequately evaluating and addressing PD in patients with self-reported MA, highlighting the fundamental role of the psychologist/psychiatrist before TKA, according to the development of our algo- 
rithm. To build a more accurate picture of the problem, further research on the topic must understand all the known factors associated with patient satisfaction.

Author Contributions: Conceptualization, P.P., M.A.O. and B.D.1.T.; methodology, P.P. and B.D.1.T.; software, P.P., M.A.O. and B.D.1.T.; validation, J.B., M.A.O. and B.D.1.T.; formal analysis, P.P. and B.D.l.T.; investigation, P.P., B.D.l.T., J.B. and M.A.O.; resources, M.A.O. and J.B.; data curation, P.P., M.A.O., J.B. and B.D.1.T.; writing—original draft preparation, P.P. and B.D.l.T.; writing—review and editing, P.P., M.A.O., J.B. and B.D.l.T.; supervision, B.D.l.T.; project administration, M.A.O. and J.B.; funding acquisition, J.B. and B.D.l.T. All authors have read and agreed to the published version of the manuscript.

Funding: This study was supported by SECOT (Spanish society of orthopedic and traumatological surgery) and B2017/BMD-3804 MITIC-CM.

Institutional Review Board Statement: The study was conducted according to the guidelines of the Declaration of Helsinki, and approved by the Institutional Review Board REG: 2017/PI0617.

Informed Consent Statement: Written informed consent has been obtained from the patients to publish this paper.

Data Availability Statement: The datasets generated for this study are available on request to the corresponding author.

Conflicts of Interest: The authors declare no conflict of interest.

\begin{tabular}{ll}
\multicolumn{2}{l}{ Abbreviations } \\
TKA & total knee arthroplasty \\
OA & osteoarthritis \\
MA & metal allergy \\
N & nickel \\
Cr-Co & chromium-cobalt \\
MSH & Metal skin hypersensitivity \\
PD & psychological distress \\
Pre-PD & preoperative Psychological Distress \\
BMI & body mass index \\
SPT & skin patch test \\
PS TKA & posterior-stabilized \\
WOMAC & Western Ontario McMaster Universities Osteoarthritis Index \\
SF-12 & questionnaire Short Form 12 questionnaire \\
Euro-Qol-5D & The EQ-5D-5L questionnaire essentially consists of two pages: the EQ-5D \\
L-VAS & descriptive system and the EQ visual analogue scale (EQ VAS). \\
PCP & primary care physician \\
PHQ-15 & questionnaires Patient Health Questionnaire Spanish version \\
SD & standard deviation
\end{tabular}

\section{References}

1. Benz, T.; Angst, F.; Lehmann, S.; Aeschlimann, A. Association of the sense of coherence with physical and psychosocial health in the rehabilitation of osteoarthritis of the hip and knee: A prospective cohort study. BMC Musculoskelet. Disord. 2013, 14, 159. [CrossRef]

2. Pérez-Prieto, D.; Gil-González, S.; Pelfort, X.; Leal-Blanquet, J.; Puig-Verdié, L.; Hinarejos, P. Influence of Depression on Total Knee Arthroplasty Outcomes. J. Arthroplast. 2014, 29, 44-47. [CrossRef] [PubMed]

3. Cuevas-Castillejos, H.; Cuevas-Castillejos, J.E. Alergia e hipersensibilidad: Conceptos básicos para el pediatra. Rev. Mex. Pediatr. 2012, 79, 192-200.

4. Ibarra, B.; García-García, J.; Azuara, G.; Vázquez-Lasa, B.; Ortega, M.A.; Asúnsolo, Á.; San Román, J.; Buján, J.; García-Honduvilla, N.; De la Torre, B. Polylactic-co-glycolic acid microspheres added to fixative cements and its role on bone infected architecture. J. Biomed. Mater. Res. Part B Appl. Biomater. 2019, 107, 2517-2526. [CrossRef] [PubMed]

5. Feeley, B.T. Management of osteoarthritis of the knee in the active patient. J. Am. Acad. Orthop. Surg. 2010, 18, 11-18. [CrossRef] [PubMed] 
6. Azuara, G.; García-García, J.; Ibarra, B.; Parra-Ruiz, F.J.; Asúnsolo, A.; Ortega, M.A.; Vázquez-Lasa, B.; Buján, J.; San Román, J.; de la Torre, B. Experimental study of the application of a new bone cement loaded with broad spectrum antibiotics for the treatment of bone infection. Rev. Esp. Cir. Ortop. Traumatol. 2019, 63, 95-103. [CrossRef]

7. Moskowitz, R. Osteoarthritis: Diagnosis and Medical and Surgical Management, 3rd ed.; Saunders: Philadelphia, PA, USA, 2001.

8. Parvizi, J.; Gehrke, T. International consensus on periprosthetic joint infection: Let cumulative wisdom be a guide. J. Bone Jt. Surg. Am. Vol. 2014, 96, 441-449. [CrossRef] [PubMed]

9. Vogel, M.; Riediger, C.; Krippl, M.; Frommer, J.; Lohmann, C.; Illiger, S. Negative affect, type D personality, quality of life, and dysfunctional outcomes of total knee arthroplasty. Pain Res. Manag. 2019, 2019, 1-9. [CrossRef] [PubMed]

10. Granchi, D.; Cenni, E.; Tigani, D.; Trisolino, G.; Baldini, N.; Giunti, A. Sensitivity to implant materials in patients with total knee arthroplasties. Biomaterials 2008, 29, 1494-1500. [CrossRef] [PubMed]

11. Post, Z.D.; Orozco, F.R.; Ong, A.C. Metal sensitivity after TKA presenting with systemic dermatitis and hair loss. Orthopedics 2013, 36, e525. [CrossRef]

12. Bircher, A.; Friederich, N.F.; Seelig, W.; Scherer, K. Allergic complications from orthopaedic joint implants: The role of delayed hypersensitivity to benzoyl peroxide in bone-cement. Contact Dermat. 2012, 66, 20-26. [CrossRef] [PubMed]

13. Hallab, N.; Merritt, K.; Jacobs, J.J. Metal sensitivity in patients with orthopaedic implants. J. Bone Jt. Surg. Am. Vol. 2001, 83, 428-436. [CrossRef] [PubMed]

14. Willert, H.G.; Buchhorn, G.H.; Fayyazi, A.; Flury, R.; Windler, M.; Köster, G.; Lohmann, C.H. Metal-on-metal bearings and hypersensitivity in patients with artificial hip joints. A clinical and histomorphological study. J. Bone Jt. Surg. Am. Vol. 2005, 87, 28-36. [CrossRef]

15. Innocenti, M.; Carulli, C.; Matassi, F.; Carossino, A.M.; Brandi, M.L.; Civinini, R. Total knee arthroplasty in patients with hypersensitivity to metals. Int. Orthop. 2014, 38, 329-333. [CrossRef]

16. Lützner, J.; Hartmann, A.; Dinnebier, G.; Spornraft-Ragaller, P.; Hamann, C.; Kirschner, S. Metal hypersensitivity and metal ion levels in patients with coated or uncoated total knee arthroplasty: A randomised controlled study. Int. Orthop. 2013, 37, 1925-1931. [CrossRef]

17. Peña, P.; Ortega, M.A.; Buján, J.; De la Torre, B. Decrease of Quality of Life, Functional Assessment and Associated Psychological Distress in Patients with Hypoallergenic Total Knee Arthroplasty. J. Clin. Med. 2020, 9, 3270. [CrossRef] [PubMed]

18. Gong, L.; Dong, J.Y. Patient's personality predicts recovery after total knee arthroplasty: A retrospective study. J. Orthop. Sci. 2014, 19, 263-269. [CrossRef]

19. Utrillas-Compaired, A.; De La Torre-Escuredo, B.J.; Tebar-Martínez, A.J.; Barco Ángel, A.-D. Does preoperative psychologic distress influence pain, function, and quality of life after TKA? Clin. Orthop. Relat. Res. 2014, 472, 2457-2465. [CrossRef]

20. Papakostidou, I.; Dailiana, Z.; Papapolychroniou, T.; Liaropoulos, L.; Zintzaras, E.; Karachalios, T.; Malizos, K.N. Factors affecting the quality of life after total knee arthroplasties: A prospective study. BMC Musculoskelet. Disord. 2012, 13, 1-9. [CrossRef]

21. Bourne, R.B. Measuring tools for functional outcomes in total knee arthroplasty. Clin. Orthop. Relat. Res. 2008, 466, 2634-2638. [CrossRef]

22. Lavernia, C.J.; Villa, J.M.; Iacobelli, D.A. What is the role of mental health in primary total knee arthroplasty? Clin. Orthop. Relat. Res. 2015, 473, 159-163. [CrossRef] [PubMed]

23. Rolfson, O.; Eresian, C.K.; Franklin, P.; Bohm, E.; Lübbeke, A.; Denissen, G.; Dunn, J.; Chenok, K.E.; Dunbar, M.; Overgaard, S.; et al. Patient-reported outcome measures in arthroplasty registries report of the patient-reported outcome measures working group of the inter- national society of arthroplasty registries part, I. overview and rationale for patient-reported outcome measures. Acta Orthop. 2016, 87, 3-8. [CrossRef] [PubMed]

24. Sanz Ortiz, J. Value and quantification of quality of life in medicine. Med. Clin. 1991, 96, 66-69.

25. Goh, G.S.; Liow, M.H.; Bin Abd Razak, H.R.; Tay, D.K.; Lo, N.N.; Yeo, S.J. Patient-reported outcomes, quality of life, and satisfaction rates in young patients aged 50 years or younger after total knee arthroplasty. J. Arthroplast. 2017, 32, 419-425. [CrossRef] [PubMed]

26. Faschingbauer, M.; Renner, L.; Boettner, F. Allergy in total knee replacement. does it exist?: Review article. HSS J. 2017, 13, 12-19. [CrossRef]

27. Benson, T.; Williams, D.H.; Potts, H.W. Performance of EQ-5D, howRu and Oxford hip \& knee scores in assessing the outcome of hip and knee replacements. BMC Health Serv. Res. 2016, 16, 512-519.

28. Conner-Spady, B.L.; Marshall, D.A.; Bohm, E.; Dunbar, M.J.; Loucks, L.; Al Khudairy, A.; Noseworthy, T.W. Reliability and validity of the EQ-5D-5L compared to the EQ-5D-3L in patients with osteoarthritis referred for hip and knee replacement. Qual. Life Res. 2015, 24, 1775-1784. [CrossRef]

29. Mell, S.P.; Wimmer, M.A.; Lundberg, H.J. Sensitivity of total knee replacement wear to variability in motion and load input: A parametric finite element analysis study. J. Orthop. Res. 2020, 38, 1538-1549. [CrossRef]

30. Gallo, J.; Goodman, S.B.; Konttinen, Y.T.; Wimmer, M.A.; Holinka, M. Osteolysis around total knee arthroplasty: A review of pathogenetic mechanisms. Acta Biomater. 2013, 9, 8046-8058. [CrossRef]

31. Namba, R.S.; Cafri, G.; Khatod, M.; Inacio, M.C.; Brox, T.W.; Paxton, E.W. Risk factors for total knee arthroplasty aseptic revision. J. Arthroplast. 2013, 28, 122. [CrossRef] 
32. Bravo, D.; Wagner, E.R.; Larson, D.R.; Davis, M.P.; Pagnano, M.W.; Sierra, R.J. No Increased Risk of Knee Arthroplasty Failure in Patients with Positive Skin Patch Testing for Metal Hypersensitivity: A Matched Cohort Study. J. Arthroplast. 2016, 31, $1717-1721$. [CrossRef] [PubMed]

33. Thakur, R.R.; Ast, M.P.; McGraw, M.; Bostrom, M.P.; Rodriguez, J.A.; Parks, M.L. Severe persistent synovitis after cobaltchromium total knee arthroplasty requiring revision. Orthopedics 2013, 36, e520. [CrossRef] [PubMed]

34. Schalock, P.C.; Crawford, G.; Nedorost, S.; Scheinman, P.L.; Atwater, A.R.; Mowad, C.; Brod, B.; Ehrlich, A.; Watsky, K.L.; Sasseville, D.; et al. Patch Testing for Evaluation of Hypersensitivity to Implanted Metal Devices: A Perspective From the American Contact Dermatitis Society. Dermatitis 2016, 27, 241-247. [CrossRef]

35. Ziemssen, T.; Kerrn, S. Psychoneuro-immunology-cross-talk between the immune and nervous systems. J. Neurol. 2007, 254 (Suppl. S2), 8-11. [CrossRef]

36. Priyadarshini, S.; Aich, P. Effects of psychological stress on innate Immunity and metabolism in humans: A systematic Analysis. PLoS ONE 2012, 7, 1-14. [CrossRef]

37. Chen, K.; Dai, X.; Li, L.; Chen, Z.; Cui, H.; Lv, S. Patellar resurfacing versus nonresurfacing in total knee arthroplasty: An updated meta-analysis of randomized controlled trials. J. Orthop. Surg. Res. 2021, 16, 83. [CrossRef] [PubMed]

38. Grassi, A.; Compagnoni, R.; Ferrua, P.; Zaffagnini, S.; Berruto, M.; Samuelsson, K.; Svantesson, E.; Randelli, P. Patellar resurfacing versus patellar retention in primary total knee arthroplasty: A systematic review of overlapping meta-analyses. Knee Surg. Sports Traumatol. Arthrosc. 2018, 26, 3206-3218. [CrossRef] [PubMed] 